opinions, fashioned, I suspect, by neuronal networks wired by individual scientific and social experience.

In the end, it is not de Duve's answers that make Vital Dust important. Its significance - and the sheer enjoyment it provides - lies in the struggle with great questions and the exuberant drive to explain the intricate complexities of living things. Anyone who contemplates biology seriously will eventually be called to a similar journey. What good fortune that we have de Duve's elegant volume for our Baedeker.

Andrew $H$. Knoll is in the Department of Organismic and Evolutionary Biology, Harvard University, Cambridge, Massachusetts 02138 , USA.

\section{All consuming}

\section{David Moore}

The Physiology of Fungal Nutrition. By D. H. Jennings. Cambridge University Press: 1995. Pp. 622. £85, \$150.

IN these days of research assessment exercises that denigrate scholarship as not contributing to the research quality of a department, it may be ungenerous to describe a book as a work of scholarship. However, and I mean this in the best possible sense and with sincerity, here is a work of high scholarship that will serve as a source of guidance and reference for many years to come.

The treatment is comprehensive (there are 126 pages of references) and up to date, but it is also rigorous and critical. Dubious experimental approaches and over-indulgent claims do not escape this author's eye. Every point is presented in detail, what is presented can be relied on, and uncertainties, gaps in knowledge or insufficiently exploited but promising approaches are identified and suggested as targets for further research.

Although Jennings says that he "cannot claim that [the book] is encyclopaedic", the contents cover all that can reasonably be considered relevant to fungal nutrition. Organized in 14 chapters, the text deals with fungal structures and processes (such as walls and membranes, the vacuolar compartment and translocation) as well as nutrients, which are organized into elemental groups (carbon compounds, nitrogen, metals, water and so on). The book is generally well produced and there are only a few (mainly trivial) typographical errors. The logical organization and helpful index allow specific items to be found fairly easily. Most of what might need to be known about a topic to give a vivid 'state of the art' picture is here.

Jennings also claims that he has "avoided referring. . . to other eukaryotic organisms" but, thankfully, this is not entirely true. It would have been a pity if the reader had missed the opportunity to benefit from the author's expertise in and knowledge of plant physiology. Fortunately, a good deal of pertinent and interesting plant physiology appears in asides or brief comparisons.

If this self-imposed boundary is overstepped, others are carefully maintained. After mentioning contrasting ideas about fungal wall growth, for instance, Jennings baldly states that "[it] is not proposed to enter into that debate here". The reader's train of thought is thus kept firmly on the rails. There is a price to pay for this single-mindedness. The text is not an easy read. Physiology is a hard task-master, requiring a bit of mathematics here, a touch of biophysics there, a pinch of basic chemistry and, increasingly these days, a sprinkling of molecular biology. Jennings carries it all off with aplomb, but the rigorous academic demands may be off-putting to many undergraduate students, and possibly some postgraduates too. But perhaps that's as it should be. The book supports rather than supplants the teacher. The arrangement of topics will not be to everyone's taste, and teachers will probably have to devise their own favourite ways of easing the student's progress through the field. But the resource is here.

From now on, and well into the next century, lecture hand-outs, tutorial reading lists and essay study guides around the world will be liberally sprinkled with references to Jennings, 1995. At last we have a real fungal physiology text.

David Moore is in the School of Biological Sciences, University of Manchester, Manchester M13 9PT, UK.

\section{Picture this}

\section{Peter Brimblebecombe}

Atmosphere, Climate and Change. By Thomas E. Graedel and Paul J. Crutzen. W. H. Freeman/Scientific American Library. Pp. 196. \$32.95, £19.95.

AREAS of science allied to natural history have always attracted wide public interest. Since Victorian times there have been many finely illustrated works on meteorology. But the breadth of twentieth-century atmospheric science and its emphasis on numerical modelling and chemical kinetics act as a barrier to the general reader. Atmosphere, Climate and
Change is a simplified version of the authors' earlier textbook (Atmospheric Change: An Earth System Perspective, W. H. Freeman, 1994; for a review see Nature 367, 695 (1994)). The new book is superbly produced, with wonderful typography, fine paper and excellent binding. It is a delight to hold. These well known scientists approach the subject with a discussion of long-term climate change and move on to atmospheric chemistry and modelling.

The writing is interesting and full of allusion to art, literature and everyday experience - all calculated to maintain the reader's interest. There are a few omissions, such as the contemporary issue of PM-10 and public health. Great care has been taken to convey scientific ideas; for example a diagram of the $\mathrm{pH}$ scale is marked with lemon juice, vinegar and milk. Yet this chapter contains around 30 chemical reactions embedded in the text. Although I appreciate the need for equations, I suspect that the ordinary reader will find these ones beyond comprehension. Perhaps they should have been put into separate sections that could be skipped by nonscientists.

Colour plates catch the reader's attention, yet I often found their captions and sometimes even the pictures themselves - puzzling. Sandro Botticelli's "The Birth of Venus" does not seem the ideal illustration of the association of wind, water and sunshine and the origin and maintenance of life. Quite the contrary: this highly allegorical picture has been thought to contrast the barrenness of the sea with the civilizing fecundity of the land. I do not regard the satanic vision of Constantin Meunier's "In the Black Country" as an example of chimneys viewed with civic pride. His preoccupation with working conditions of miners and labourers makes this most unlikely. It is admirable to use art to place science within the context of human experience. But the difficulties with the illustrative material in this book should remind us that picture editing requires just as much care as the review of science.

I hope non-experts will enjoy this book. It is a wonderful introduction to the intricacies of a modern science relevant to serious questions confronting humankind.

Peter Brimblecombe is in the School of Environmental Sciences, University of East Anglia, Norwich NR4 7TJ, UK.

Cambridge University Press has just published Basic Physical Chemistry for the Atmospheric Sciences by Peter V. Hobbs. It aims to provide a clear and concise review of basic principles for undergraduates. Contains more than 150 exercises. $£ 40$ (hbk), $£ 14.95$ (pbk). 